\title{
Design and evolution of the Seafarer's Health Passport for supporting (tele)-medical assistance to seafarers
}

\author{
Giulio Nittari ${ }^{1}$, Antonio Arcese ${ }^{2}$, Gopi Battineni ${ }^{1}$, Krutika Khuman $^{3}$, Graziano Pallotta $^{1}$, \\ Andrea Saturnino $^{4}$, Fabio Sibilio ${ }^{2}$, Francesco Amenta ${ }^{1,2}$ \\ ${ }^{1}$ Telemedicine and Telepharmacy Centre, School of Medicinal and Health Products Sciences, University of Camerino, Italy \\ ${ }^{2}$ Technological Development Group, CIRM SERVIZI Srl, Rome, Italy \\ ${ }^{3}$ Research Department, 3 Cube Services Pte. Ltd., Singapore \\ ${ }^{4}$ Research Department, International Radio Medical Centre (CIRM), Rome, Italy
}

\begin{abstract}
Background: Seafarers undergo periodic medical examination for their employment. This information in most cases is not effectively used when requesting for medical assistance during service on board ships. The medical history of an individual is important for provision of medical care and can be critical to the outcome. There is growing adoption of digital applications and electronic health records that are adding great value to the care provided. The Seafarer's Health Passport (SHP) is an application specifically designed for improving the quality of medical assistance provided to seafarers both through telemedicine or classic medical check-ups in ports/hospitals worldwide. The SHP provides a secure and unique way to archive and retrieve the seafarer's medical history in an electronic support.

Materials and methods: The SHP that we have developed is a product with specific hardware and software specifications. The basic features of this software are Linux operating system Debian/Ubuntu, Apache Web server 2.x, Server database MySQL/Maria DB PHP programming language 5.6.xx, and secure connection in https.

Results: The SHP represents a helpful hint to physicians providing medical advices to seafarers enabling them to make more decisions that are informed and curtailing possible complications due to misdiagnosis. Conclusions: Provision of high quality medical assistance requires knowledge of patient's medical history. The availability of an easy access and friendly use system of own medical history is useful for a population of travellers, such as seafarers to guarantee a reasonable level of medical care at any time.
\end{abstract}

(Int Marit Health 2019; 70, 3: 151-157)

Key words: seafarers, electronic health record, medical information management, health passport, personal health tracking

\section{INTRODUCTION}

Shipping is one of the world's oldest professions. Due to the nature and duration of their voyage, ships could be on the high seas for days or weeks before going back on shore [1-5]. Most merchant ships have less than 25 crewmembers onboard and according to the Maritime Labour Convention (MLC) 2006 [6] are not required to carry a healthcare professional. It is a duty of the ship's captain to take care of the crew's health [1-5]. According to MLC
2006, all measures should be taken to ensure that seafarers onboard are provided with quality healthcare services, which are like those offered onshore. Due to the optimised workforce and the importance of the crew health, ship owners and managers are keen to provide prompt and effective medical assistance to sailing crew [3, 6].

The fact that ships with no medical facilities are at sea for a given elapse of time before they can reach a port, makes seafarers in a disadvantageous condition compared 
to ashore workers which can be reached by a health professional within less than 1 hour [1]. In this situation, the only possible, solution developed thanks to the invention of radiotelegraphy by Guglielmo Marconi in 1897, is to provide medical advice to ships via telecommunication systems [7]. From the beginning of $21^{\text {th }}$ century, advanced telemedicine solutions are taking the place of medical assistance via radio and this can result in a real improvement of the assistance delivered to people on board ships $[1,5,7]$.

The physician taking care of a remote patient has never seen the patient and probably will never see him/her [7] and knowledge of the medical history of a seafarer is a prerequisite for delivering high quality medical assistance at sea. Healthcare systems and services compatible with electronic records are particularly dynamic due to their accessibility, quality, and efficiency provided by information technology developments. Electronic health record (EHR), used during clinical encounters, has become increasingly popular all around the world [8, 9]. Information and communication technologies defined as "electronic health" may also increase the capability to identify target groups of patients for specific interventions, improving clinical healthcare quality, especially for specific patient groups [10, 11]. Clinical information, called "personal health record", refers to the collection of data about an individual's health and health care, stored electronically [9-11]. In general, an EHR is integrated with a hardware and software platform, which provides and supports a dataset for each patient [9]. The present study consisted in the development of a Seafarer Health Passport (SHP) device/system dedicated to the collection and storage of medical data that can be accessed if and when a seafarer requires medical attention.

\section{MATERIALS AND METHODS}

The SHP collects in an easy accessible system seafarer's medical history with the purpose to use these data everywhere and at any time when necessary. The purpose of the initiative is to share patient clinical data through online services accessible to users and their doctors depending on the user's choice, for an efficient and rapid health service delivery.

\section{IDENTIFICATION OF DATA TO BE COLLECTED IN THE SHP}

Analysis of International Labour Office guidelines [12] and discussion with doctors working at Centro Internazionale Radio Medico (CIRM, International Radio Medical Centre), the Italian Telemedical Assistance Services (TMAS), resulted in us drafting the minimum data required for the tool. The minimum information that the tool must record are shown in Table 1.

Based on this information an EHR dedicated for the specific needs of seafarers was developed. The system allows seafarers access to their medical history if a need
Table 1. Minimum health information of a seafarer that should be included in the Seafarer's Health Passport

\begin{tabular}{ll}
\hline Type of information & Details \\
\hline Personal information & Name, rank, age, nationality \\
Medical history & Family and personal medical history \\
Basic data & Height, weight, body mass index \\
Medical data & $\begin{array}{l}\text { Blood pressure, blood glucose and } \\
\text { other essential vitals }\end{array}$ \\
& $\begin{array}{l}\text { Previous clinical tests and laboratory } \\
\text { results if available } \\
\text { Medical notes }\end{array}$ \\
& $\begin{array}{l}\text { Allergies, prescriptions, medicines } \\
\text { taken chronically etc. }\end{array}$
\end{tabular}

arises. Each seafarer thanks to the SHP will have always with him/her his/her medical data. Medical data will be contained in a water-proof personalised USB drive provided to each seafarer.

\section{SOFTWARE AND HARDWARE SPECIFICATIONS FOR THE SHP}

The basic features of the software in this project are Linux operating system Debian/Ubuntu, Apache Web server 2.x, Server database MySQL/Maria DB PHP programming language 5.6.xx, and secure connection in https. For securing the data completely, the access to the application is only permitted from an internal connection and therefore not directly from a connection outside.

- USB Version: 2.0 or higher USB with minimum 4 GB space for storage of medical information.

- Operating System: Windows. Web Version: Access to internet. Chrome or Safari browser.

- How the system works: A company signs up for the service to cover their seafarers with the SHP. Candidates will be invited to sign-up for the tool. The candidate provides consent for using the application and using the various features of the application. The candidate syncs his account with the User Identifier (UID). This step is essential for integration of his pre-employment medical records to be synced with his SHP.

\section{DATA PROTECTION}

Medical information is highly sensitive [13]. Data protection and privacy represent the first goal of the system, with the SHP conceived to include two types of information, those freely accessible and those password-protected. Freely accessible information will include name and surname of the seafarer, place and date of birth, home address, blood group, any eventual major allergy, date of the fitting certificate, results of it and who issued it. The remaining information are password-secured and cannot be accessed 


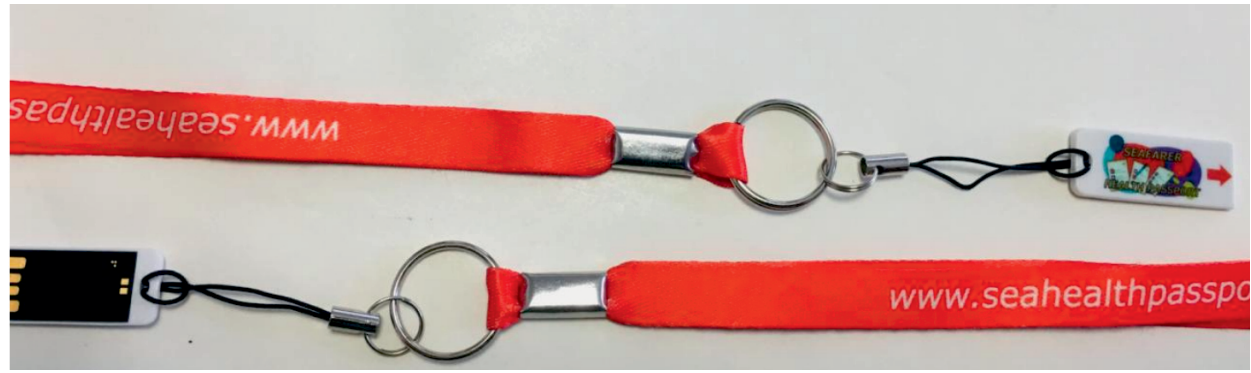

Figure 1. The Seafarer's Health Passport device

unless the password is known. The system is totally General Data Protection Regulation (GDPR) $[14,15]$ compliant and servers collecting SHP medical data are located in the European Union (Italy) $[14,15]$ to guarantee to the user of the service the highest levels of data protection worldwide.

The seafarer will be asked whether he/she wants to have disclosed his/her confidential medical information in case of medical emergencies. The seafarer's wishes should be clearly indicated in the informed consent form. Upon receiving the authorisation to disclose the seafarer's medical information, these will be shared with the ship's captain or with the doctor/ /hospital taking care of the patient. If not authorized the wishes of the seafarer/patient should be respected.

\section{RESULTS}

The software SHP collects in an easy accessible system the medical history of seafarers with the purpose to use these data everywhere and at any time when necessary. It consists of a water-proof personalised USB drive provided to each seafarer (Fig. 1). Insertion of the USB device in a PC launches software containing seafarer medical data accessible to users and their doctors, for an accurate health service delivery.

\section{SEAFARER HEALTH PASSPORT WORKFLOW AND ORGANISATION}

The procedures of how to comply with data protection regulations and ensure complete confidentiality the process are summarised below. The shipping company is provided with a secure login to upload list of the seafarers for which the company has subscribed the service. The pre-employment medical centre is provided with a secure link to upload the medical reports of the seafarer. This link is automatically generated when an appointment is created by the company for the seafarer at the specific medical centre. As an alternative possibility, the candidate can upload his own medical records.

Figure 2 shows the SHP home page of an imaginary seafarer. On opening the application we have first an access page A. After access the seafarer is directed into a menu to choose among 7 different sections $\mathbf{B}$. The "about me" section C includes the seafarer's personal data, whereas the "emergency contacts" section D indicates who to contact in case of need. This section can be updated and modified autonomously by the seafarer.

Figure 3 shows where the seafarer medical history can be found $(A)$ and the section for uploading the results of new medical data $(B)$ for updating the contents of the SHP.

Through the sections "vitals and measurement" (Fig. 4), the seafarer can have access to his own vital signs $(A)$ and weight $(B)$ values.

The SHP has been already introduced as a form of trial to seafarers working for CMA CGM (France) and Marnavi (Italy). No problems or difficulties were raised by the approximately 600 seafarers using it on a voluntary basis. The idea was very much appreciated and people feel themselves safer and with an additional health protection in case of diseases on ships (data not shown). The information contained in the SHP are shared with the TMAS for use in case of request of telemedical advice.

\section{DISCUSSION}

An EHR is a digital version of a patient's paper chart $[8,9]$. EHRs are real-time, patient-centred records that make information available instantly and securely to authorised users. While an EHR does contain the medical and treatment histories of patients, an EHR system is built to go beyond standard clinical data collected in a provider's office and can be inclusive of a broader view of a patient's care. One of the key features of an EHR is that health information can be created and managed by authorised providers in a digital format capable of being shared with other providers across more than one health care organisation. EHRs are built to share information with other health care providers and organisations - such as laboratories, specialists, medical imaging facilities, pharmacies, emergency facilities, and school and workplace clinics - so they contain information from all clinicians involved in a patient's care.

The present work has summarised the development of a portable electronic device, the SHP collecting health data of a particular population of travellers as seafarers. 


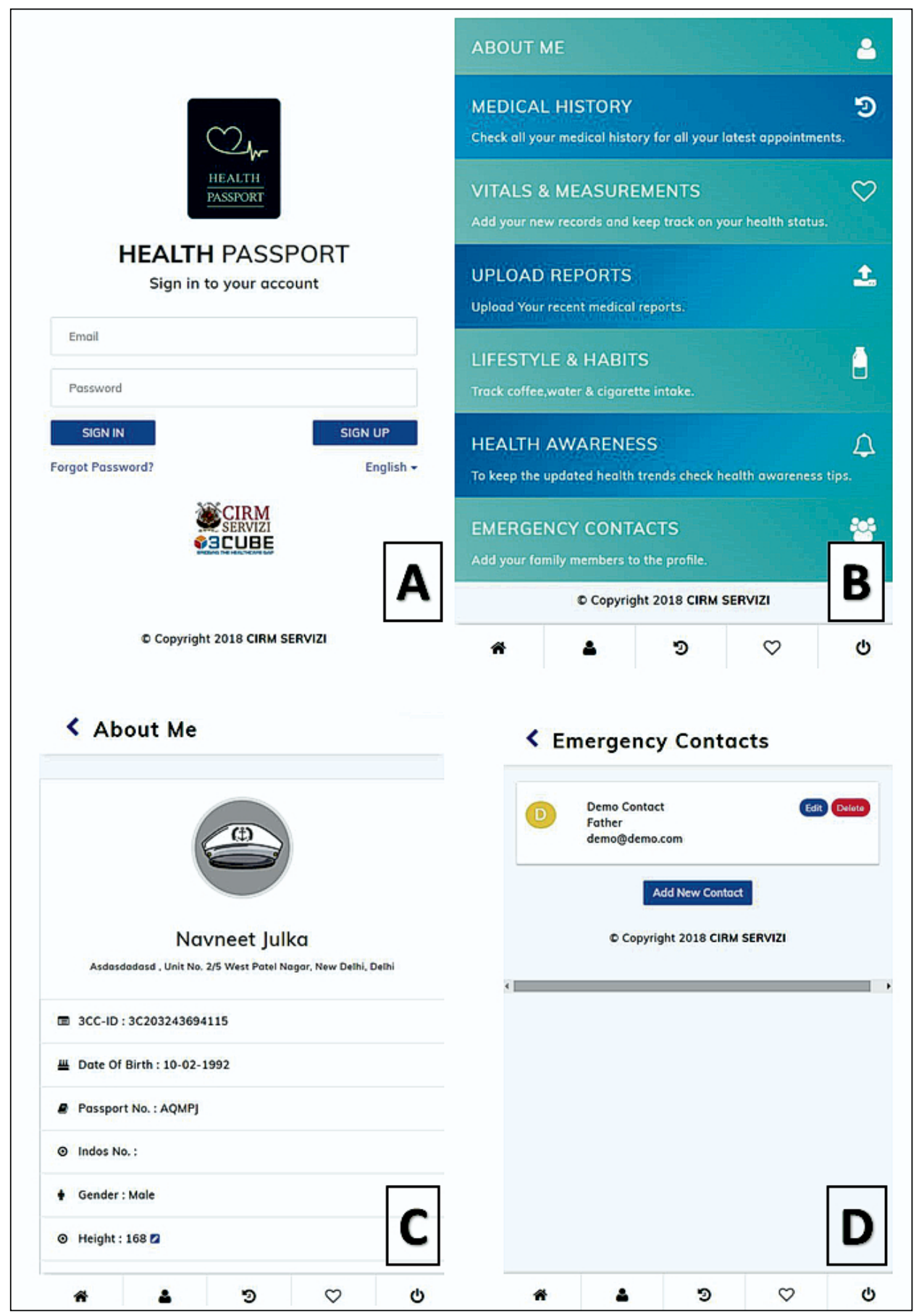

Figure 2. Home page (A) of the Seafarer's Health Passport, menu of the sections of it (B), basic seafarer personal data (C) and emergency contacts (D)

Thanks to the SHP health data of seafarers travel with the worker that can access his own medical information at any time and anywhere making them available for medical assistance at sea, visits in ports or hospitalisation. The SHP offers several opportunities in the area of crew health and can lead to a more informed and healthier workforce and may represent the first step for improving the quality of medical care of seafarers.
A first step of our work was an extensive interaction with various stakeholders from which we have identified several areas of concerns which have been discussed. In terms of protection of health information, the seafarer alone has access to his medical information. However, as part of the enhanced crew care programme and based on his consent, this information will be shared with medical doctors who may need to review them in 


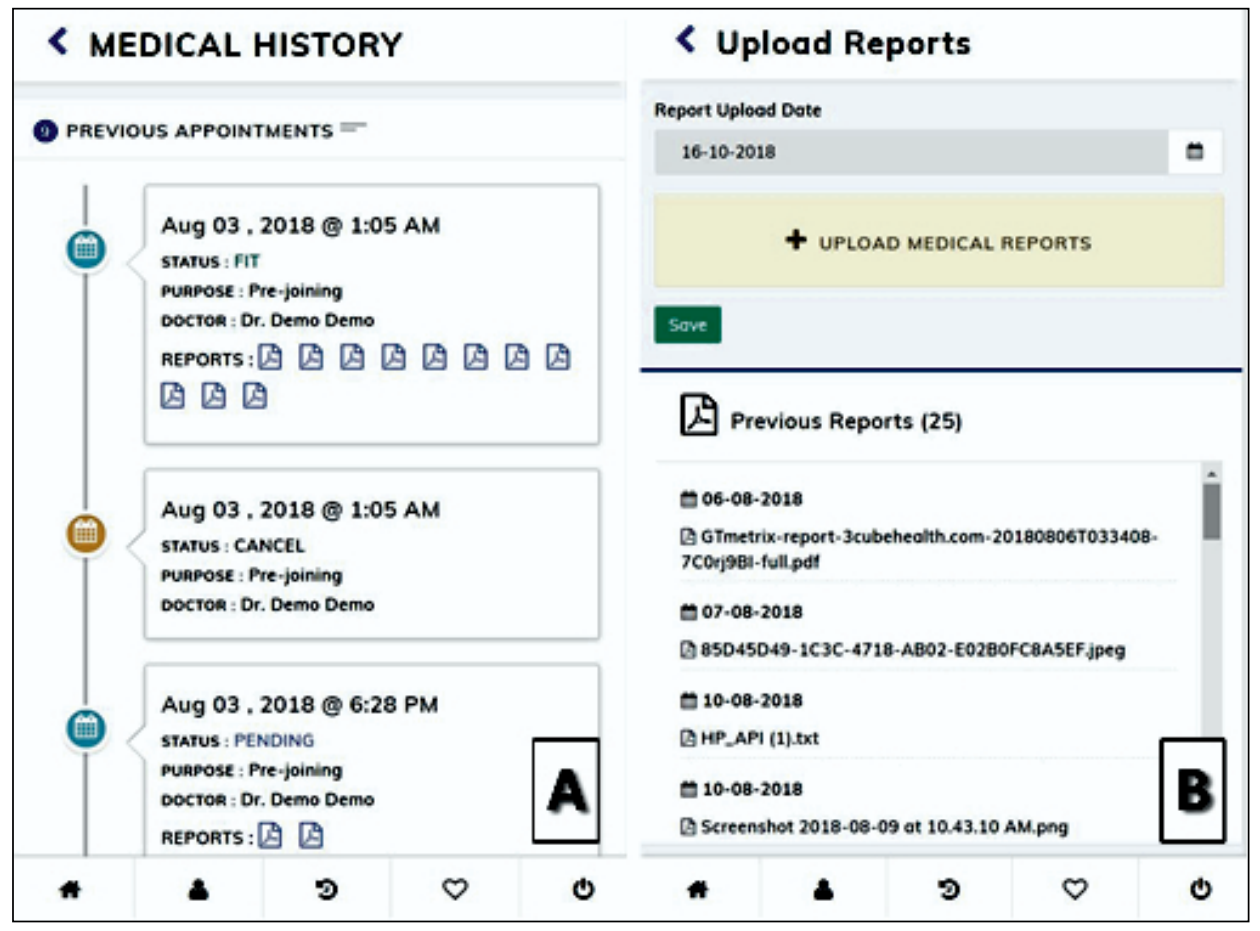

Figure 3. The medical history section of the Seafarer's Health Passport. The seafarer can find in this section the files of the reports of his medical visits uploaded by recruiting clinics and shared with Telemedical Assistance Services (A). Updated reports or the results of new clinical tests that can be downloaded by the seafarer through the section shown in panel $B$

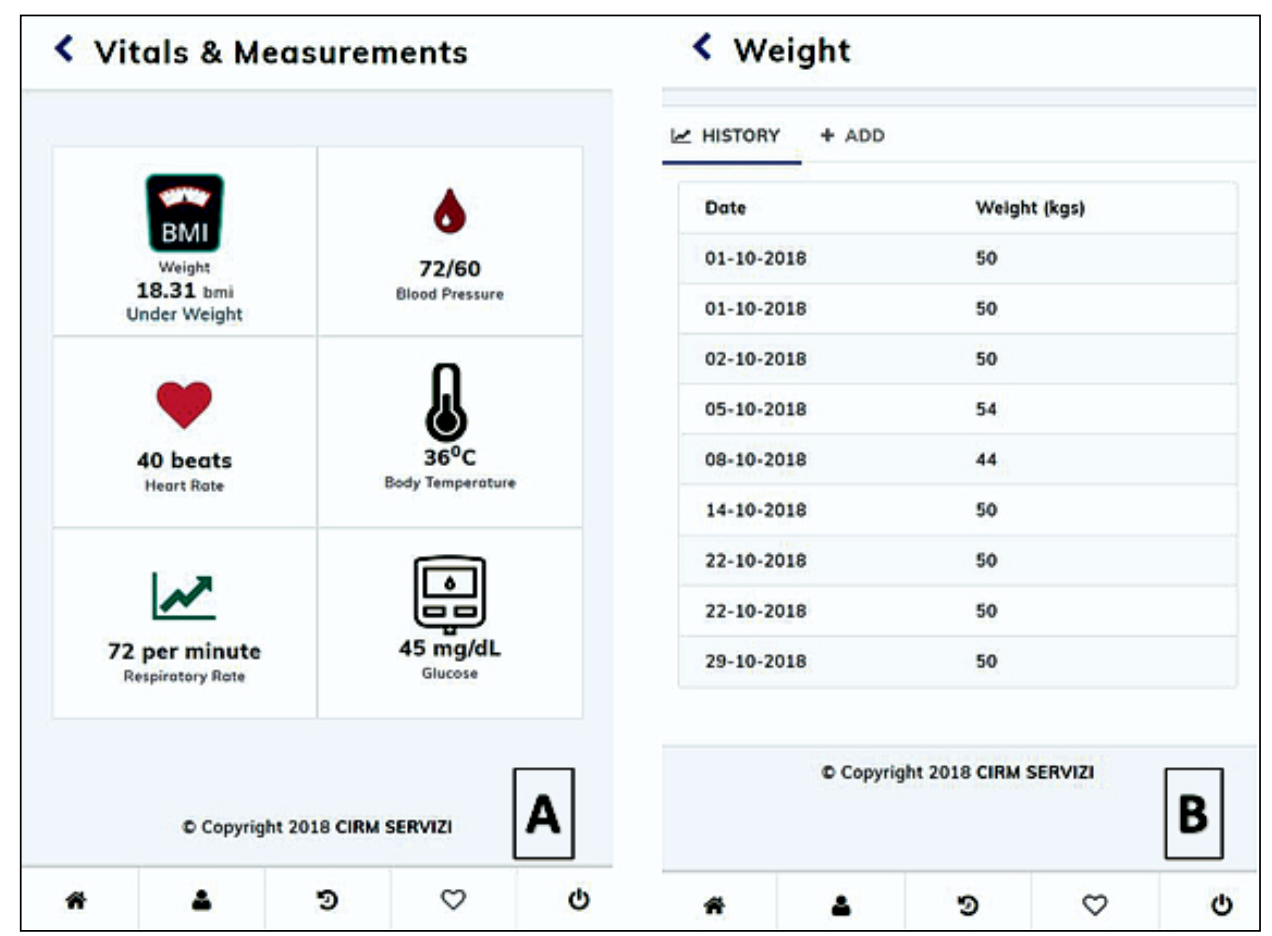

Figure 4. Two screen shots of the Vitals and Measurement section of the Seafarer's Health Passport (SHP). At any time the seafarer can review his basic vital data (A) stored in the SHP, and other health information as for instance body weight (B). These data constitute a diary that the seafarer is free to consult 
case of medical events. The system will continuously evolve to provide automated alerts, reminders and tips on the seafarer's health which the individual can use as a guideline to stay healthy. In terms of GDPR requirements [15] a user can ask for his personal information to be deleted at any time. The debate on the ownership of health data is still ongoing and no definite conclusions have been reached. The account and data added by the individual will be wiped off. However, data added by other data points such as pre-employment medical centres or companies which are only synced with SHP will be de-linked and cease to be referred in the SHP databases. If the seafarer chooses to be forgotten while being serviced by his employer, the employer will be notified of this change. The seafarers can continue to use the SHP as a personal health record application if they stay subscribed to the service.

The subscription can be paid for by the employer or the individual. Once the subscription ends, the account will be made inactive for a definite period within which it can be re-activated. Telemedicine may solve the problem of healthcare related to remote patients, like seafarers, which do not have direct and/or easy access to medical services. Several studies indicate the transforming nature of telemedicine in health care. For seafarers it is an important resource on the high seas. For more effective tele medical services, it is essential to have access to the medical histories of the seafarers to allow physicians to be more informed and conclusive on their diagnosis and treatment. SHP can reveal the clinical history of the patient over time and this peculiarity reduces the need to track down patients' previous paper medical records. Therefore, SHP is a real innovation in making the telemedicine system as easiest as possible. It decreases the risk of lost paperwork, leads to a reduction of misdiagnoses which contribute to $10 \%$ of patient deaths. It can contribute to keep the patients and physician safe, and cuts out billing of accountants-commercialist and lawyers $[8,9]$.

The SHP is the beginning of a whole new perspective of crew care. The tool can be used to keep the seafarer engaged with his/her health by conducting timely health surveys, mental health questionnaires, provide personalised care to the seafarer by analysing the health data and providing preventive or proactive measures. Big data analysis in the future can indicate the trend of health concerns globally and areas of attention required and provide means of making pre-employment medicals more adaptive and effective. For instance, a definite diagnosis of allergies is needed to establish adequate treatment options and proper preventive measures [13].

\section{CONCLUSIONS}

The SHP is a promising tool to improve the efficiency and efficacy of telemedical and medical support to seafarers. Based on the experience obtained in the maritime environment, it can also be beneficial for people with limited or difficult access to medical facilities. On the other hand, it can be a useful data resource to support comparative. In this study, we have considered maritime workers. They work in a particularly dangerous environment, far from the land, and without a physician close to them. This innovation can contribute to change the life of citizen as well as of specific categories of workers.

The SHP is not only a useful indicator for the employer but also to medical doctors required to provide remote assistance. However, the ultimate beneficiary of the tracking, timely awareness and other value-added features of the tool is the seafarer, who could use this facility as a good tool for measuring his own health conditions and fitness throughout his active life.

\section{ACKNOWLEDGEMENTS}

The authors are greatly indebted to Dr Marc Samad, Médicin Conseil of CMA CGM, Marseille (France) for the suggestions and useful discussions. The support and the provision of data from CIRM (International Radio Medical Centre, Rome, the Italian TMAS), and the Centre of Telepharmacy and Telemedicine of the University of Camerino (Italy) are gratefully acknowledged. We thank 3 Cube Services Pte. Ltd. (Private Limited company in Singapore) for their collaboration to the study and for providing insights on the development of the Seafarer Health Passport. We would like to thank Marnavi SpA and CMA Ships SA for their collaboration to evaluation of the SHP. This research was funded by CIRM $(0.5 \%$ charitable tax-free donations) and University of Camerino, Department of Telemedicine and Telepharmacy supported this study. Drs Nittari, Battineni and Pallotta received a PhD bursary from the University Camerino.

\section{REFERENCES}

1. Amenta F, Dauri A, Rizzo N. Telemedicine and medical care to ships without a doctor on board. J Telemed Telecare. 1998; 4 (Suppl 1): 44-45, doi: 10.1258/1357633981931407, indexed in Pubmed: 9640732.

2. Amenta F. The International Radio Medical Centre (C.I.R.M.): an organization providing free medical assistance to seafarers of any nationality worldwide. Int Marit Health. 2000; 51(1-4): 85-91, indexed in Pubmed: 11214116.

3. Ricci G, Pirillo I, Rinuncini C, et al. Medical assistance at the sea: legal and medico-legal problems. Int Marit Health. 2014; 65(4): 205-209, doi: 10.5603/IMH.2014.0039, indexed in Pubmed: 25522704.

4. Norum J, Moksness SG, Larsen E. A Norwegian study of seafarers' and rescuers' recommendations for maritime telemedicine services. J Telemed Telecare. 2002; 8(5): 264-269, 
doi: $10.1177 / 1357633 \times 0200800504$, indexed in Pubmed: 12396854

5. Guitton MJ. Telemedicine at sea and onshore: divergences and convergences. Int Marit Health. 2015; 66(1): 18-21, doi: 10.5603/ IMH.2015.0005, indexed in Pubmed: 25792161.

6. International Labour Organization (ILO), Maritime Labour Convention, ILO, Geneva 2016.

7. Mahdi SS, Amenta F. Eighty years of CIRM. A journey of commitment and dedication in providing maritime medical assistance. Int Marit Health. 2016; 67(4): 187-195, doi: 10.5603/IMH.2016.0036, indexed in Pubmed: 28009394.

8. Evans RS. Electronic Health Records: Then, Now, and in the Future. Yearb Med Inform. 2016; Suppl 1: S48-S61, doi: 10.15265/IYS2016-s006, indexed in Pubmed: 27199197.

9. Ayatollahi $\mathrm{H}$, Mirani $\mathrm{N}$, Haghani $\mathrm{H}$. Electronic health records: what are the most important barriers? Perspect Health Inf Manag. 2014; 11: 1c, indexed in Pubmed: 25593569.
10. McCullough CM, Wang JJ, Parsons AS, et al. Quality measure performance in small practices before and after electronic health record adoption. EGEMS (Wash DC). 2015; 3(1): 1131, doi: 10.13063/2327-9214.1131, indexed in Pubmed: 25848635.

11. Frankel RM. Computers in the Examination Room. JAMA Intern Med. 2016; 176(1): 128-129, doi: 10.1001/jamainternmed.2015.6559, indexed in Pubmed: 26619228.

12. International Labour Office. Guidelines on the Medical Examinations of Seafarers. ILO Geneva 2013.

13. Callens S, Cierkens K. Legal aspects of E-HEALTH. Stud Health Technol Inform. 2008; 141: 47-56, indexed in Pubmed: 18953124.

14. Shenoy A, Appel JM. Safeguarding confidentiality in electronic health records. Camb Q Healthc Ethics. 2017; 26(2): 337-341, doi: 10.1017/S0963180116000931, indexed in Pubmed: 28361730.

15. General Data Protection Regulation (GDPR). Regulation (EU) 2016/679 of the European Parliament and of the Council of 27 April 2016. 